\title{
Two methods of measuring muscle tone applied in patients with decerebrate rigidity
}

\author{
S A TSEMENTZIS, F J GILLINGHAM, \\ A G ORDON, A N M D L A K IE \\ From the Departments of Surgical Neurology and Clinical Neurophysiology, \\ University of Edinburgh, Edinburgh
}

SUMMARY Two methods were used to measure muscle tone in patients with decerebrate rigidity. In the first method forces of square waveform were applied and the calculated compliance of the joint was used as an index of rigidity. Oscillatory transients were seen at the same frequency as the physiological tremor. The range of normal variation in compliance was large and the values measured in the patients fluctuated markedly which limited the value of this index. In the second method, where forces of sinusoidal waveform were employed, the resonant frequency of the joint was measured and used as an index of rigidity. This index proved reliable and reproducible.

Muscle tone is normally estimated by the subjective assessment of the resistance encountered when a limb is passively moved. This, however, is liable to human error, the more so when normal physiological variations in muscle tone often occur. Instrumentation which would reproduce the manoeuvres adopted in the clinical assessment of muscle tone is highly desirable.

There are two traditional techniques for the measurement of muscle tone: (1) the monitoring of electromyographic activity (EMG), based on the principle that increased muscle contraction is associated with increased electrical activity under physiological conditions (Hoefer and Putnam, 1940; Levine et al., 1964), and (2) the measurement of the resistance of a passively moved limb, with or without EMG recording (Brumlic and Boshes, 1961; Webster, 1964; Nashold, 1966).

The advantages and limitations of both methods have been discussed in the symposia on skeletal muscle hypertonia (Levine, 1964) and on Parkinson's disease (Nashold and Huber, 1966).

Whereas the evaluation of the force changes which result from imposed position changes of a limb has been commonly used for the measurement of muscle tone, Roberts (1963) first appreci-

Address for reprint requests: Dr S A Tsementzis, Department of Surgical Neurology, Western General Hospital, Crewe Road South, Edinburgh EH4 2XU.

Accepted 24 May 1979 ated the importance of selecting force rather than position changes as the independent variable. In experiments on decerebrate cats he showed that the imposition of changes in length on muscles produced irregular and unpredictable fluctuations in tension. In contrast, the responses to changes in the applied force were much more consistent.

Wilkie (1950) has shown that the velocity of the movement and the EMG response are both dependent on the frequency and amplitude of the applied force. Granit (1970) and Jansen and Rudjord (1964) have shown that the muscle receptors of a cat are responsive to changes in force rather than in position. This has also been shown to be the case for at least some of the corticospinal neurones in man (Evarts, 1967).

Sinusoidal forces have also been used successfully for the evaluation of the dynamic properties of the muscle receptors and of the stretch reflex (Jansen and Rack, 1966; Terzuolo and Poppele, 1968). Bertholz and Metral (1970) applied sinusoidal forces to the forearm under visual control of limb position in order to make a frequency analysis of the neuromuscular control mechanisms of the elbow joint. Joyce et al. (1974) used a flywheel device to apply sinusoidal displacement rather than force to the elbow, but displacement and force are not equivalent in nonlinear systems, such as the skeletomuscular (Machin and Pringle, 1960; Roberts, 1963). Similarly, displacement 
rather than force was measured by Duggan and McLellan (1973) in their study of the resonant frequency of the elbow and evaluation of its muscle tone. Agarwal and Gottlieb (1975) examined the effects of forced low frequency sinusoidal oscillations on the ankle joint of normal subjects but this method presented problems due to the action of gravity on the limb under examination.

In the present study we quantified decerebrate rigidity by measuring in the wrist the changes in the displacement and its angular velocity which resulted from variations in an applied torque, either sinusoidal or square in waveform.

The method was developed in the Department of Clinical Neurophysiology, University of Edinburgh, and has been used successfully for the study of the servocontrol of the posture of the normal human wrist (Walsh, 1970a, 1973) and jaw (Walsh, 1970b). It has also been used in the study of tremor (Walsh, 1969) and clonus (Walsh, 1971; Harris and Walsh, 1972). It is much more versatile than previous devices and is applicable to virtually any distal joint, Whereas other contemporary methods are investigating length changes in response to imposed tension changes, this method was designed to allow the muscle to "choose" whether to keep its length constant and allow its tension to fluctuate, or to keep the tension constant and allow its length to fluctuate.

\section{Subjects and methods}

Thirteen head-injured patients with decerebrate rigidity were selected for study as having a welldeveloped rigidity on clinical assessment. Ten of the cases were investigated in the acute stage of decerebrate rigidity-that is, as soon as possible after surgery and a short interval on mechanical ventilation in order to stabilise the arterial gas tensions. When instrumentation had been set up and several measurements of muscle tone had been obtained the relaxant drugs were allowed to wear off. Decerebrate rigidity soon developed and measurements were repeated over a period, at the end of which the patient was returned to mechanical ventilation.

The other three cases, who suffered from posttraumatic hydrocephalus, still exhibited severe decerebrate rigidity three to four weeks after injury. They were examined repeatedly and also provided the opportunity to study the effects on rigidity of diazepam (10 mg intramuscularly or continuously by intravenous infusions of $5-10 \mathrm{mg} /$ $\mathrm{kg}$ body weight/24 hours) and chlorpromazine hydrochloride (repeated doses of $25-50 \mathrm{mg}$ intramuscularly).

Twenty-four volunteers were used as control subjects. They were divided into two groups in order to determine whether forces of square (10 subjects) or sinusoidal (14 subjects) waveform would give the more reliable and consistent results. The period of study was limited to $20-30$ minutes on each subject because measurements of muscle tone are highly susceptible to the onset of fatigue.

A printed circuit motor was used to apply alternating torques to the wrist. This device is quite different from the conventional electric motor in various aspects.

The printed motor's armature is a formation of many flat copper wires connected together in a pancake configuration and embedded in heat resistant plastic to form a disc. Brushes which deliver the supply power to the motor press against one side of the disc and run on the flat surface of the protruding copper wires thereby acting as a commutator for the system (fig 1). The inductance of the armature is trivial because there is no iron in its magnetic circuit and this allows the development of rapidly generated forces. The armature has low inertia and so affects the mechanical properties of the limb minimally. The arrangement of the copper wires allows the printed motor to run smoothly at all speeds, eliminating cogging effects. The torque generated by the motor is directly proportional to the current applied to it by a transistorised power amplifier.

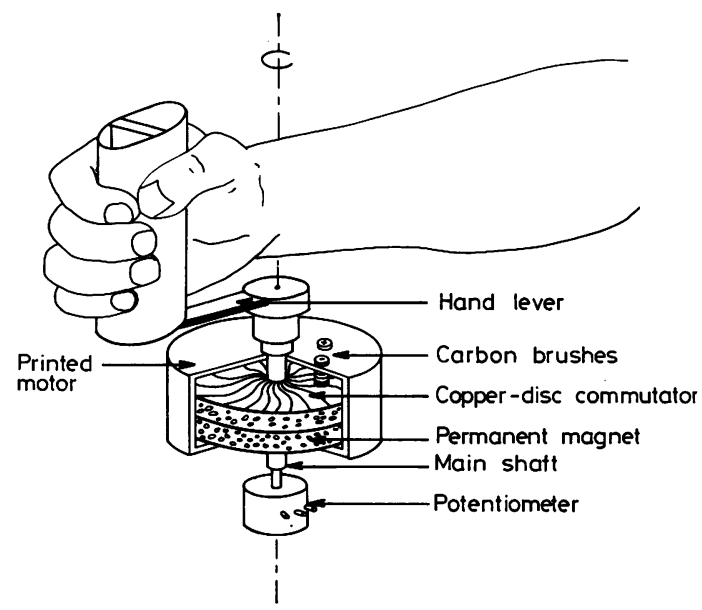

Fig 1 Schematic cut-away view of a torque generator and arrangement for testing muscle tone of the right wrist. The wrist is firmly bandaged to a splint and attached co-axially with the torque generator. The motion is in the horizontal plane. 
Since a precise control of force is required, a feedback loop was used so that errors in the force were compensated automatically by adjusting the current supply to the motor. Sine, square, or triangular waves can be supplied by an appropriate waveform generator, and thus a variety of torque patterns can be provided.

A conductive plastic potentiometer was coupled to one end of the motor spindle while the other end was coupled to the examined limb through a specially made metal splint. The limb was strapped firmly to avoid losses of the motion. The motion of the joint of the limb was in the horizontal plane. The hand was attached to the spindle so that the wrist joint and the printed motor were co-axial (fig 1). The potentiometer recorded the angular position of the limb. The velocity was registered by means of an operational amplifier. Surface electromyographic recordings were accomplished by using suction cup rubber electrodes filled with jelly and attached over the flexor and extensor muscles of the limb, two over each muscle group $50 \mathrm{~mm}$ apart.

The torque, position, velocity, and EMG data were all graphically displayed by means of a Minograph ink jet recorder. The method has been described in more detail by Walsh (1974).

\section{Results}

LOW FREQUENCY ABRUPTLY REVERSING TORQUES OF SQUARE WAVEFORM

Normal control subjects

Torque-position changes By means of slow square waves of displacement of constant amplitude, and reversing abruptly from extension to flexion and vice versa every few seconds, torques were delivered to the hand. As seen in the position trace, the hand moved in the same direction until a steady level was reached after an initial overshoot followed by a few decrementing oscillations. In a fully relaxed subject the amplitude of these oscillations was greater in flexion of the hand than in extension and their frequency varied from 1.5$2.0 \mathrm{~Hz}$ in flexion and $1.0-1.5 \mathrm{~Hz}$ in extension.

When the subject stiffened voluntarily, the displacement of the hand was reduced and it was virtually fixed in the middle position. The frequency of the oscillations was increased proportionally to the degree of effort (ranging from $3.0-8.9 \mathrm{~Hz}$ ) while their amplitude was greatly reduced. The first oscillation was the largest and brought the hand back to its starting point almost immediately.

Electromyography When reciprocating forces were applied to the wrists of the relaxed subjects, myotatic activity-that is, a burst of electrical activity of a stretched muscle-was observed mainly in the extensor muscles. Moderately stiff voluntary contraction against a background of tonic activity enhanced the myotatic activity, mainly in the extensor muscles during flexion and less so in the flexors during extension (fig 2). Out of 10 subjects, seven showed definite myotatic activity of the extensors and only four of the flexor muscles. Myotatic activity was most prominent as the torque was reversed and it was directly affected by the torque. As assessed on the EMG, greater forces produced greater activity. Myotatic activity disappeared when the subject was maximally stiff.

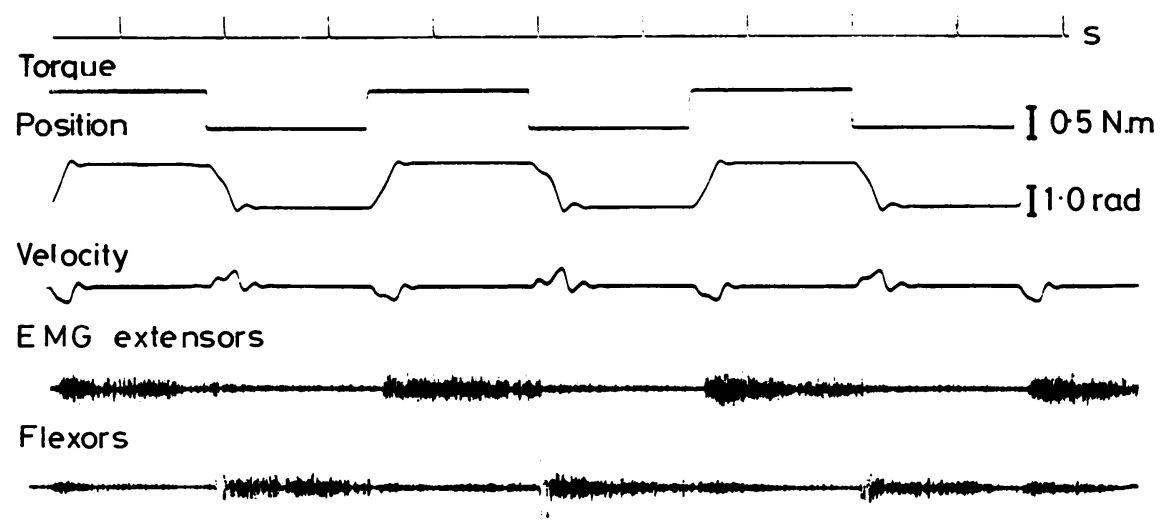

Fig 2 Myotatic activity seen in both extensor and flexor muscles of the forearm produced by the application of an abruptly reversing torque of square waveform in a normal relaxed wrist. 
Instead of showing the usual myotatic activity, two relaxed subjects to whom square reciprocating forces were applied developed shortening reactions (Sherrington, 1909). Removal of tension sometimes caused reappearance of muscular activity after a short interval and without obvious change in the mechanical parameters (torque, position, and velocity) to account for this phenomenon.

The average amplitude of electrical activity of the extensor muscles was $9 \mu \mathrm{V}$ and $11 \mu \mathrm{V}$ for the flexors on voluntary relaxation. This activity, however, was increased at maximal stiffening up to $144 \mu \mathrm{V}$ in the extensors and $95 \mu \mathrm{V}$ in the flexors, a significant shift of balance towards the extensors (table 1).

Measurement of muscle tone Joint compliance, defined as the ratio of displacement to applied force, reflects changes in muscle tone. A normally relaxed joint moves easily and has high compliance, whereas the compliance of a tense or rigid limb is low.

The angular displacement of the wrist (measured in radians, rads) per unit of applied torque (Newton metres, N.m), was calculated. This is, the compliance of the system and is used as an index of muscle tone. (In this case, $1.0 \mathrm{rad}$ displacement per 0.35 N.m on the recorder, represents a compliance of $2.86 \mathrm{rad} / \mathrm{N} . \mathrm{m}$.)

The EMG was also monitored and its amplitude (in microvolts, $\mu \mathrm{V}$ ) was correlated with compliance values (table 1 ).

Summarised results from 10 normal volunteers are presented in table 1. The average compliance of all subjects during voluntary full relaxation was $2.06 \mathrm{rad} /$ N.m. During maximal stiffening this was reduced to $0.43 \mathrm{rad} /$ N.m. The scatter, however, among individuals was great; the SD was $\pm 0.84 \mathrm{rad} / \mathrm{N} . \mathrm{m}$ during relaxation and $\pm 0.20 \mathrm{rad} /$ N.m during stiffening. This means that the resistance to passive movement differs considerably between individuals. Occupation, age, or sex did not affect these results. This variability in the baseline compliance during relaxation is reflected in the wide range of changes in compliance when the subject went maximally stiff. When compliance values during relaxation were plotted against similar values at maximal stiffening an overlap was found.

\section{Patients with decerebrate rigidity}

Torque-position changes The wrist, initially at rest in the midposition, moved in the same direction as the applied torque - that is, from extension to flexion and vice versa. This displacement reached a steady level after an overshoot and decrementing oscillations as with the control subjects. When the patient relaxed spontaneously, the EMG activity was minimal and the oscillations were of the same amplitude and frequency as in the control subjects. During a severe decerebrate spasm, however, oscillations of greater frequency (up to $12 \mathrm{~Hz}$ ) were recorded than in the control subjects while their amplitude was similar (fig 3). When inertia was added to the hand of one patient

Table 1 Summarised results of wrist compliance and EMG activity of the forearm muscles of 10 normal volunteers during voluntary full relexation and maximal stiffening

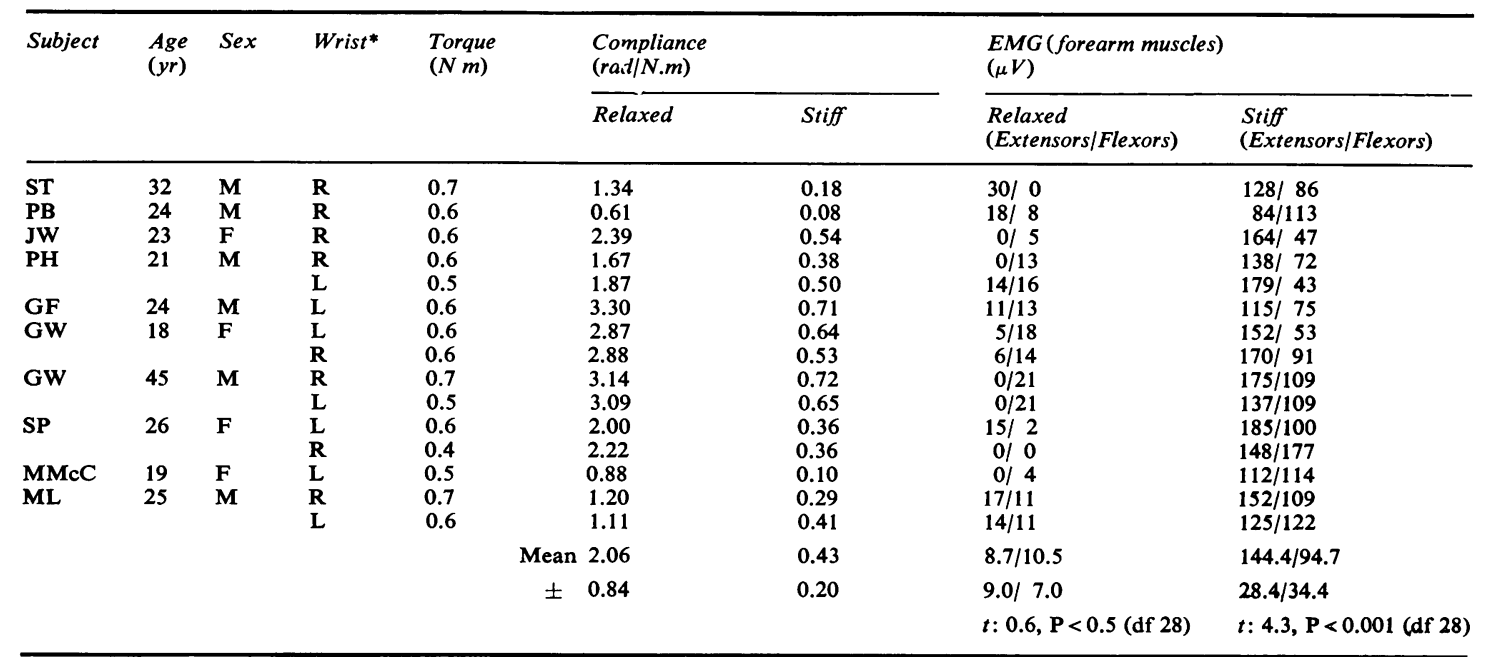

${ }^{*} \mathrm{R}=$ right, $\mathrm{L}=$ left. 


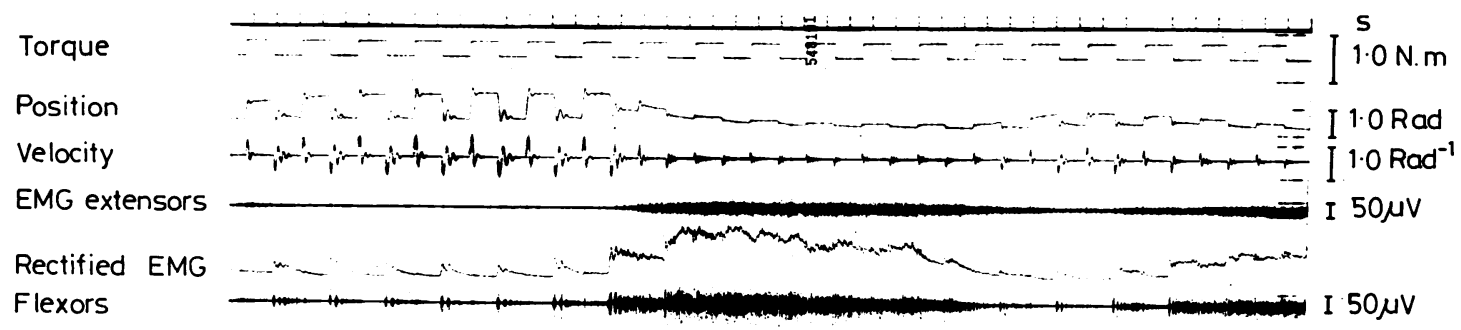

Fig 3 Oscillatory transients at 3-3.5 Hz during spontaneous relaxation increasing up to $11-12 \mathrm{~Hz}$ during decerebrate rigidity. Wrist compliance (displacement/torque) is reduced in proportion to the degree of rigidity.

by adding iron weights to the crank, the oscillatory frequency was decreased in inverse proportion to the inertia-that is the greater the inertia the more the reduction in oscillatory frequency and vice versa. With the subject rigid the oscillation frequency was $7.78 \mathrm{~Hz}$; the mean frequency was $6.81 \mathrm{~Hz}$ when $0.0025 \mathrm{~kg} \cdot \mathrm{m}^{2}$ was added to the system, with $0.005 \mathrm{~kg} \cdot \mathrm{m}^{2}$ it was $5.93 \mathrm{~Hz}$ and with $0.01 \mathrm{~kg} \cdot \mathrm{m}^{2}$ the mean frequency was reduced to $3.83 \mathrm{~Hz}$. Throughout the period of recording the EMG of flexor and extensor muscles of the forearm remained unchanged.

Electromyography Simultaneous study of the EMG at rest showed myotatic activity which was more pronounced in the extensor than in the flexor muscles in all patients but one who showed the reverse. Myotatic activity was observed only when rigidity was minimal against a background of tonic muscle discharge. During decerebrate spasms no myotatic activity was present, although not infrequently myotatic activity preceded the tonic discharge (Granit, 1975). Forces too small to elicit stretch responses in the normal subjects produced detectable stretch responses in decerebrate subjects.

Shortening reactions were observed in only four patients. They were brief and intermittent and the electrical activity of both muscle groups was small. Measurement of rigidity Wrist compliance was calculated in all patients with decerebrate rigidity; summarised results are presented in table 2. Mean compliance during spontaneous relaxation was

Table 2 Summarised results of left wrist compliance and EMG activity of forearm muscles of patients with decerebrate rigidity during spontaneous relaxation, relaxation achieved by pharmacological agents, and decerebrate rigidity

\begin{tabular}{|c|c|c|c|c|c|c|c|c|c|c|c|c|c|}
\hline \multirow[t]{4}{*}{ Case } & \multirow{4}{*}{$\begin{array}{l}\text { Age } \\
(y r)\end{array}$} & \multirow[t]{4}{*}{$\operatorname{Sex}$} & \multirow{4}{*}{$\begin{array}{l}\text { Torque } \\
(N . m)\end{array}$} & \multicolumn{10}{|c|}{ Joint compliance (rad/N.m) and EMG activity of forearm muscles ( $\mu$ V; extensors/flexors) } \\
\hline & & & & \multicolumn{2}{|c|}{ Spontaneous relaxation } & \multicolumn{6}{|c|}{ Relaxation produced by } & \multicolumn{2}{|c|}{ Decerebrate rigidity } \\
\hline & & & & \multirow[t]{2}{*}{$(\mathrm{rad} / N . m)$} & \multirow[t]{2}{*}{$(\mu V)$} & \multirow{2}{*}{\multicolumn{2}{|c|}{$\begin{array}{l}\begin{array}{l}\text { Pancuronium } \\
\text { bromide }\end{array} \\
(\mathrm{rad} / N . \mathrm{m})(\mu V)\end{array}$}} & \multirow{2}{*}{\multicolumn{2}{|c|}{$\begin{array}{l}\text { Diazepam } \\
\overline{(\mathrm{rad} / \mathrm{N} . \mathrm{m})(\mu V)}\end{array}$}} & \multirow{2}{*}{\multicolumn{2}{|c|}{$\begin{array}{l}\begin{array}{l}\text { Chlorpromazine } \\
\text { hydrochloride }\end{array} \\
(\mathrm{rad} / \mathrm{N.m})(\mu V)\end{array}$}} & \multirow[t]{2}{*}{$(\mathrm{rad} / N . m)$} & \multirow[t]{2}{*}{$(\mu V)$} \\
\hline & & & & & & & & & & & & & \\
\hline \multirow[t]{3}{*}{$\begin{array}{l}\text { BS } \\
\text { AB } \\
\text { IL } \\
\text { JW } \\
\text { GMcD } \\
\text { DC } \\
\text { MJ } \\
\text { SC } \\
\text { AM } \\
\text { GB } \\
\text { AN } \\
\text { DT } \\
\text { NMcL }\end{array}$} & $\begin{array}{r}25 \\
10 \\
19 \\
8 \\
58 \\
27 \\
9 \\
14 \\
8 \\
53 \\
26 \\
20 \\
18\end{array}$ & $\begin{array}{l}\mathbf{M} \\
\mathbf{M} \\
\mathbf{M} \\
\mathbf{F} \\
\mathbf{M} \\
\mathbf{M} \\
\mathbf{M} \\
\mathbf{M} \\
\mathbf{M} \\
\mathbf{M} \\
\mathbf{M} \\
\mathbf{F} \\
\mathbf{M}\end{array}$ & $\begin{array}{l}0.6 \\
0.9 \\
0.9 \\
0.9 \\
0.5 \\
0.5 \\
0.9 \\
0.9 \\
0.9 \\
0.9 \\
0.5 \\
0.9 \\
0.5\end{array}$ & $\begin{array}{l}2.88 \\
0.96 \\
1.23 \\
1.93 \\
2.68 \\
2.67 \\
0.89 \\
1.21 \\
2.95 \\
1.17 \\
3.00 \\
3.09 \\
2.79\end{array}$ & $\begin{array}{r}22 / 28 \\
10 / 10 \\
17 / 17 \\
14 / 15 \\
34 / 31 \\
32 / 17 \\
5 / 12 \\
27 / 9 \\
21 / 7 \\
7 / 5 \\
18 / 0 \\
18 / 10 \\
22 / 6\end{array}$ & $\begin{array}{l}4.78 \\
1.25 \\
1.64 \\
2.85 \\
4.27\end{array}$ & $\begin{array}{l}4 / 7 \\
3 / 2 \\
0 / 6 \\
4 / 3 \\
4 / 4\end{array}$ & $\begin{array}{l}2.90 \\
0.75\end{array}$ & $\begin{array}{r}8 / 10 \\
5 / 9 \\
12 / 6\end{array}$ & 2.84 & $10 / 0$ & $\begin{array}{l}1.51 \\
0.09 \\
0.16 \\
0.28 \\
0.60 \\
0.46 \\
0.10 \\
0.10 \\
0.46 \\
0.10 \\
0.47 \\
0.39 \\
0.25\end{array}$ & $\begin{array}{c}128 / 96 \\
151 / 111 \\
158 / 119 \\
150 / 160 \\
213 / 170 \\
240 / 58 \\
50 / 168 \\
120 / 79 \\
125 / 109 \\
133 / 79 \\
126 / 110 \\
210 / 70 \\
119 / 58\end{array}$ \\
\hline & & & $\begin{array}{r}\text { Mean } \\
\pm\end{array}$ & $\begin{array}{l}2.11 \\
0.88\end{array}$ & $\begin{array}{r}19.0 / 13.0 \\
8.9 / 8.8\end{array}$ & $\begin{array}{l}2.83 \\
1.36\end{array}$ & $\begin{array}{l}4.0 / 3.0 \\
2.3 / 2.5\end{array}$ & $\begin{array}{l}2.39 \\
1.45\end{array}$ & $\begin{array}{l}8.0 / 8.0 \\
3.5 / 2.0\end{array}$ & $\begin{array}{l}2.73 \\
0.16\end{array}$ & $\begin{array}{c}10.0 / 12.0 \\
0.7 / 16.2\end{array}$ & $\begin{array}{l}0.38 \\
0.38\end{array}$ & $\begin{array}{r}148.0 / 107.0 \\
49.5 / 39.2\end{array}$ \\
\hline & & & Student's & $t$ test: & $\begin{array}{l}1.77 \\
P<0.1\end{array}$ & $\begin{array}{l}1.53+ \\
P<0.01\end{array}$ & $\begin{array}{l}1.00 \\
P<0.2\end{array}$ & $\begin{array}{l}0.45+ \\
P<0.5\end{array}$ & & $\begin{array}{l}0.95+ \\
P<0.2\end{array}$ & & & $\begin{array}{r}2.43\left(^{*}\right) \\
\mathrm{P}<0.025\end{array}$ \\
\hline
\end{tabular}

* =significant.

$+=$ as compared with values at spontaneous relaxation. 
$2.11 \mathrm{rad} / \mathrm{N} . \mathrm{m} \pm 0.88$ whereas during maximal rigidity this was reduced to $0.38 \mathrm{rad} / \mathrm{N} . \mathrm{m} \pm 0.38$. The scatter among individuals as with the normal subjects, was great in both conditions and there was an overlap in the values.

During muscular paralysis with pancuronium bromide the compliance was insignificantly $(t: 1.53, \mathrm{P}<0.1)$ increased $(2.83 \mathrm{rad} / \mathrm{N} . \mathrm{m} \pm 1.36)$ from its value during spontaneous relaxation. Diazepam and chlorpromazine were less effective than the pancuronium, but which of the two is more effective in reducing rigidity can not be decided definitely because of the small number of samples.

\section{SINUSOIDAL TORQUES OF LOGARITHMICALLY VARYING FREQUENCY \\ Preliminary study}

When a sinusoidal torque of varying frequency is applied to a joint the amplitude of the resulting movement is greatest at a particular frequency because of a "resonance" phenomenon at a frequency correlated with the compliance (Walsh, 1973).

As the velocity of a joint's movement is determined by the frequency and amplitude of the applied sinusoidal force, it is necessary to investigate the relationships between (a) torque and resonance in the joint, (b) torque frequency and resonance, and (c) sweep length (an interval during which a suitable range of torque frequencies is applied) and resonance.

The wrist joint was selected for the study as being most accessible and presenting fewer mechanical problems than other peripheral joints.

Fourteen normal subjects, six males and eight females, of different handedness and widely differing body build and occupation were studied.

Sinusoidal torques were delivered to the hand which, therefore, oscillated with approximately the same phase. The peak force could be set at any level from 0.1-0.9 N.m, which is enough to agitate a human wrist vigorously, and the frequency was automatically swept frcm $1.5-21.5 \mathrm{~Hz}$ in a known time interval. Two sweep rates were used: (1) sweep rate of $1 / 3$ octave per second-that is, the frequency doubling every three seconds over a range from 1.5 to $16.0 \mathrm{~Hz}$ (a scan of this range thus taking about eight seconds), or (2) a sweep of $1 / 12$ octave per second (about 22 seconds per scan).

Effect of torque on resonance: When in a relaxed state all subjects showed a characteristic resonance of the wrist. Above a certain force threshold this resonant frequency remained constant; there was

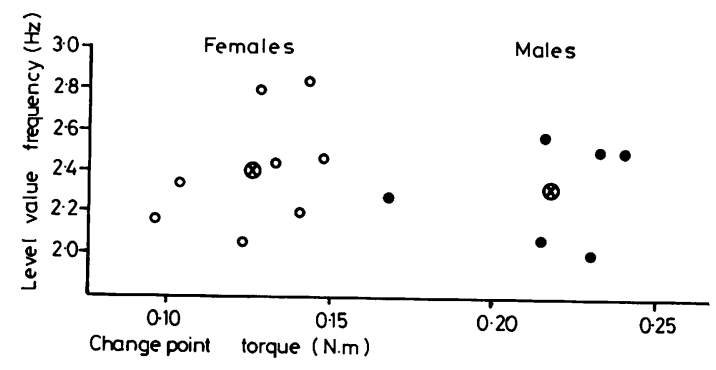

Fig 4 Torque-resonance relationsh:p between sexes. Males have a higher changeover value (threshold) than females, with no overlap in the values except for the anomalously low value in one case $(\otimes=$ mean for both sexes).

no significant difference $\left(R^{\prime}=36, P<0.1\right)$ between males (average resonance $2.33 \mathrm{~Hz}$ ) and females (average resonance $2.42 \mathrm{~Hz}$ ). Below the torque threshold value, the resonant frequency varied inversely with the torque. The threshold force value in males was 0.203 N.m. It was significantly lower in females at 0.134 N.m (at the $1 \%$ level using a Wilcoxon Rank Sum test) and there was no overlap in the values (figs 3 and 4). One subject, however, (WM, $29 \mathrm{yr}$, male) showed an anomalously low threshold. Even so, there was no overlap with the female values. In a few cases at very high torques $(\sim 0.5 \mathrm{~N} . \mathrm{m})$ the frequency deviated from its constant value at a lower level. When inertia was added to a female hand in an attempt to simulate a male hand the threshold moved in a direction opposite to that anticipated. Body build and occupation did not affect these results. The handedness of the subjects was also investigated but no consistent threshold differences were found between the two hands.

Five brothers, aged 5.5-13 years, were also investigated. All except the eldest showed a female resonance pattern. The latter, who was pubertal, showed a typical male pattern.

When subjects went as stiff as possible their resonant frequency was raised significantly, and then torque variations were without effect on the resonance of the wrist.

Effect of torque frequency on resonance When two different ranges of torque frequencies were applied consecutively, one being double the other, the resonant frequency remained unchanged.

Effect of sweep speed on resonance Conversely, by keeping the range of torque frequency constant but varying the sweep speed so that a scan of 1.5-16 $\mathrm{Hz}$ was applied during 5, 10, or 15 seconds 

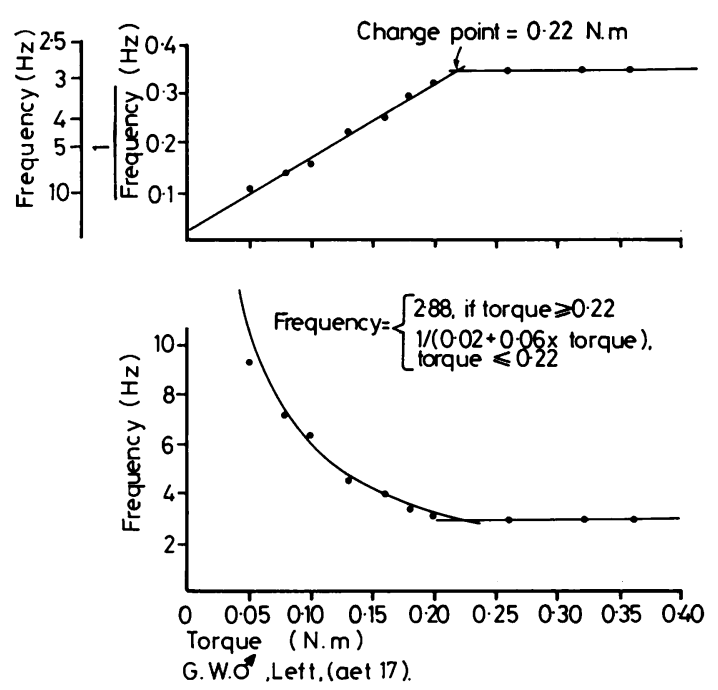

Fig 5 Torque-resonance relationship in a normal wrist. Rise in resonant frequency as torque is reduced below a threshold level.

the critical resonant frequency remained unchanged. The "envelope", however, was smoother when the sweep was longer (fig 5).

It appeared from this study that the system behaves linearly with moderate torques and becomes nonlinear when the torque is reduced below a threshold level which is different in men and women. This may reflect a difference or differences in the joint itself or in the associated tendons or muscles. The observation that one small group of prepubertal male children showed a female pattern of reaction suggests that endocrine factors must be taken into consideration. This is to be investigated further. The fact that by loading a female's hand, its torque threshold value moved in a direction opposite to that predicted, shows that there is not a simple mechanical explanation for this.

The nonlinear response of the system to low torques indicates that the system is heavily damped.

\section{Normal subjects}

Logarithmically modulated sinusoidal torques were applied to the wrist. In a relaxed subject, when torques of decreasing frequencies were used at a constant level of $0.5 \mathrm{~N} . \mathrm{m}$, the amplitude of the oscillations of the displacement and velocity tracing increased smoothly and peaked at resonance. When torques of increasing frequencies were applied at a constant torque value, they started with large excursions and after the critical resonant frequency had been attained, the amplitude of the oscillations of both the position and velocity tracings was reduced by half or a third, the so-called "jump effect" (Walsh, 1974). This effect was usually produced by using large torques. The longer the sweep, the more obvious was the effect. The jump effect appeared in nine out of 14 subjects, but in a few of them it appeared in only one hand. It always appeared at torque frequencies between $2.5-3.0 \mathrm{~Hz}$, a range just above the critical resonant frequency of the hand. The jump effect did not appear when the person went stiff voluntarily and thus increased the joint's natural frequency.

Resonance frequency Sinusoidal torques of constant amplitude $(0.25 \mathrm{~N} . \mathrm{m})$ and logarithmically modulated frequency (ranging from $1.5-21.5 \mathrm{~Hz}$ ) were delivered to both wrists of each of the 14 volunteers. The wrist, therefore, oscillated with the same phase. Resonance of the joint was recognised when the amplitude of its movement was greatest; the torque frequency at which this occurred was recorded. The resonant frequency (RF) was measured from the "envelope" of the angular velocity trace; the higher the resonant frequency the greater the rigidity and vice versa.

When the subject was relaxed, the rate of oscillation of the joint was low, the amplitude was large, and the EMG activity was absent or intermittent (fig 6). When the wrist was stiffened deliberately the rate increased, the amplitude was greatly reduced, and the EMG activity became continuous and enhanced in both flexor and extensor muscles. All of these variations were proportional to the degree of effort (fig 7).

The mean RF while the subjects were fully relaxed was $2.3 \pm 0.2 \mathrm{~Hz}$ (range $2.0-2.8 \mathrm{~Hz}$ ). When the subjects were partially stiff the mean RF increased, varying from 4.8-6.0 Hz, and stiffening the wrist as much as possible raised the mean $R F$ to $10.3 \pm 1.3 \mathrm{~Hz}$ (range $8.3-12.5 \mathrm{~Hz}$ ).

\section{Patients with decerebrate rigidity}

Resonant frequency Sinusoidal torques of constant amplitude 0.32 to 0.41 N.m, swept at frequencies similar to the controls, were delivered to the joint under examination.

During decerebrate rigidity the amplitude was reduced and both the RF and the EMG activity increased. When a patient was relaxed (spontaneously or pharmacologically), the amplitude was great, the RF $\vee$ is low, and the EMG showed little activity. 

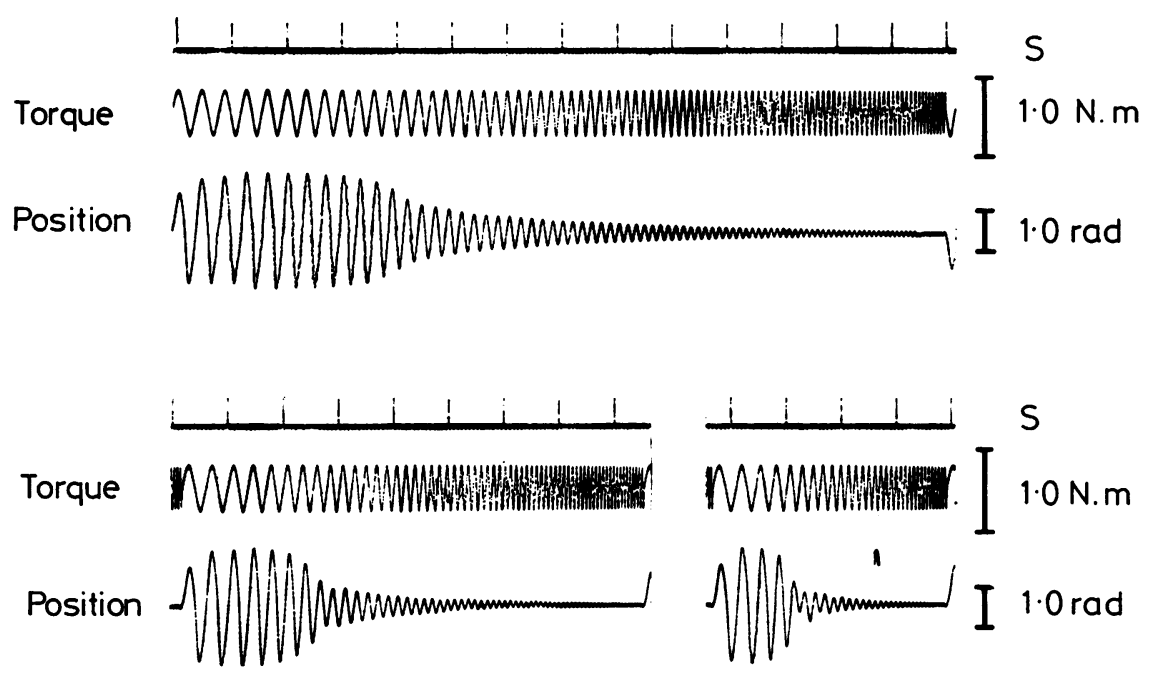

Fig 6 Effect of sweep on resonance. By keeping the range of torque frequency constant but varying the sweep length the critical resonant frequency remains unchanged. The longer the sweep (top trace) the smoother the "envelope"; by reducing the sweep length (bottom traces) a sudden reduction of amplitude "jump effect") is produced.

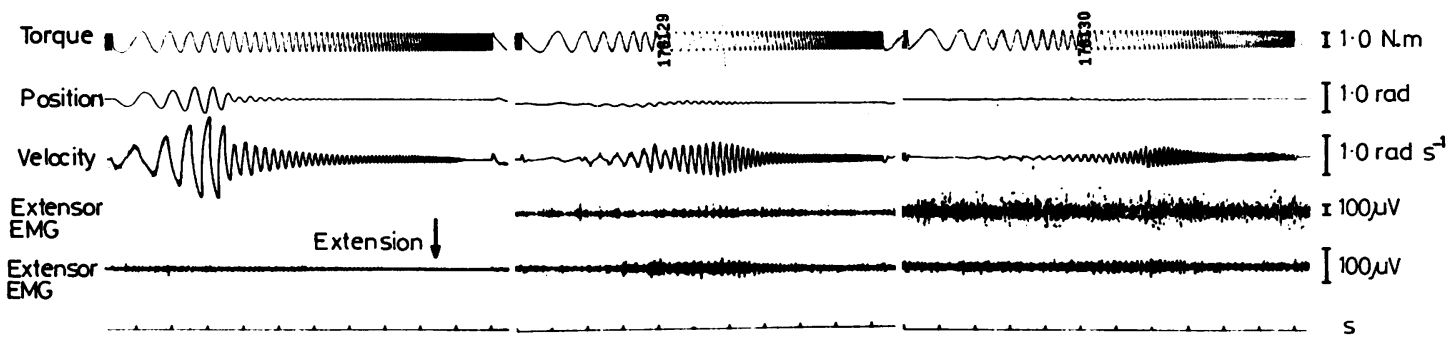

Fig 7 Sinusoidal constant torques of logarithmically increasing frequency are applied to a normal wrist. Resonance of the joint is recognised when the amplitude of its movement is greatest. The resonant frequency, which is measured from the "envelope" of the velocity trace, varies with muscle lone. Increase in muscle tone by stiffening the wrist voluncarily elevated the resonant frequency, and both extensor and flexor activity according to the degree of effort: wrist fully relaxed (left trace), partially stiff (middle trace), and as stiff as possible (right trace).

The RF during periods of greatest rigidity, spontaneous relaxation and paralysis is presented in detail in table 3. Two groups were distinguished according to the degree of rigidity. In group 1 (cases with severe rigidity), the mean RF was $9.1 \pm 1.5 \mathrm{~Hz}$ (range 7.4-11 $\mathrm{Hz}$ ). During spontaneous relaxation, however, the mean RF was reduced to $2.9 \pm 0.56 \mathrm{~Hz}$ (range $2.3-3.7 \mathrm{~Hz}$ ). In group 2 (cases with moderate rigidity) the mean
RF was $5.3 \pm 0.8 \mathrm{~Hz}$ (range $4.0-6.1 \mathrm{~Hz}$ ), while during spontaneous relaxation it was reduced to $2.4 \pm 0.3 \mathrm{~Hz}$ (range $2.2-2.8 \mathrm{~Hz}$ ).

The difference in the mean RF of groups 1 and 2 during rigidity, spontaneous relaxation, and "curarisation" was highly significant, significant, and not significant respectively (table 4).

The difference between the mean RF of the control group and that of groups 1 and 2 during 
Table 3 Measurement of muscle tone during severe (group 1) and moderate (group 2) acute decerebrate rigidity, spontaneous relaxation of the rigidity, and muscle paralysis. The resonant frequency was measured from the "envelope" of the angular velocity trace; the higher the values the higher the degree of rigidity

\begin{tabular}{|c|c|c|c|c|c|c|c|c|c|c|c|}
\hline \multirow[t]{4}{*}{ Group } & \multirow[t]{4}{*}{ Case } & \multirow{4}{*}{$\begin{array}{l}\text { Torque } \\
\text { (N.m) }\end{array}$} & \multicolumn{5}{|c|}{ Resonant frequency* } & \multicolumn{4}{|c|}{ Increase in conpliance } \\
\hline & & & \multirow{3}{*}{$\begin{array}{l}\text { Decebrate } \\
\text { rigidity } \\
(\mathrm{Hz})\end{array}$} & \multirow{3}{*}{$\begin{array}{l}\text { Spontaneous } \\
\text { relaxation } \\
(\mathrm{Hz})\end{array}$} & \multicolumn{3}{|c|}{ Relaxation by } & \multirow{3}{*}{$\begin{array}{l}\text { Spontaneous } \\
\text { relaxation } \\
(\%)\end{array}$} & \multicolumn{3}{|c|}{ Relaxation by } \\
\hline & & & & & $P$ & $D$ & $C P M$ & & $P$ & $D$ & $C P M$ \\
\hline & & & & & $(H z)$ & $(H z)$ & $(H z)$ & & $(\%)$ & $(\%)$ & $(\%)$ \\
\hline 1 & $\begin{array}{l}\text { BS } \\
\text { AB } \\
\text { IL } \\
\text { JW } \\
\text { GMcD } \\
\text { DC } \\
\text { MJ }\end{array}$ & $\begin{array}{l}0.32 \\
0.40 \\
0.32 \\
0.32 \\
0.32 \\
0.40 \\
0.41\end{array}$ & $\begin{array}{r}10.50 \\
7.76 \\
7.43 \\
10.33 \\
11.12 \\
8.37 \\
8.20\end{array}$ & $\begin{array}{l}3.72 \\
2.33 \\
2.71 \\
2.44 \\
2.86 \\
3.49 \\
3.44\end{array}$ & $\begin{array}{l}1.83 \\
1.90 \\
1.91 \\
1.90 \\
1.89\end{array}$ & $\begin{array}{l}2.12 \\
2.19\end{array}$ & 2.24 & $\begin{array}{r}684 \\
1008 \\
650 \\
1689 \\
1405 \\
471 \\
466\end{array}$ & $\begin{array}{l}3194 \\
1564 \\
1413 \\
2848 \\
3357\end{array}$ & $\begin{array}{l}1452 \\
1298\end{array}$ & 1291 \\
\hline 2 & $\begin{array}{l}\text { SC } \\
\text { AN } \\
\text { GB } \\
\text { AM } \\
\text { DT } \\
\text { NMcL }\end{array}$ & $\begin{array}{l}0.41 \\
0.33 \\
0.41 \\
0.34 \\
0.34 \\
0.34 \\
0.41\end{array}$ & $\begin{array}{l}4.02 \\
5.51 \\
4.67 \\
5.54 \\
5.43 \\
6.09 \\
6.18\end{array}$ & $\begin{array}{l}2.00 \\
2.59 \\
2.37 \\
2.25 \\
2.84 \\
2.50 \\
2.67\end{array}$ & $\begin{array}{l}1.56 \\
1.88 \\
1.90 \\
1.89 \\
1.81 \\
1.80\end{array}$ & & 2.37 & $\begin{array}{l}320 \\
349 \\
288 \\
505 \\
264 \\
490 \\
433\end{array}$ & $\begin{array}{r}770 \\
758 \\
500 \\
758 \\
800 \\
1042\end{array}$ & 788 & 586 \\
\hline
\end{tabular}

$\mathrm{P}=$ pancuronium bromide $; \mathrm{D}=$ diazepam $; \mathrm{CPM}=$ chlorpromazine hydrochloride.

$\left.{ }^{*}\right)=$ Mean resonant frequency of 20 normal wrists was $2.34 \mathrm{~Hz}$ (range $\left.2.0-2.86\right) ; \mathrm{SD} \pm 0.24$

Table 4 Difference in the mean resonant frequency (dMRF) between groups 1 and 2 during decerebrate rigidity $(D R)$, spontaneous relaxation $(S R)$, and curarisation $(\mathrm{Cu})$

\begin{tabular}{lccl}
\hline & $D R$ & $S R$ & $C u$ \\
\hline $\operatorname{dMRF}(\mathrm{Hz})$ & 3.76 & 0.44 & 0.11 \\
$\mathrm{df}$ & 12 & 12 & 9 \\
$t$ & 5.87 & 2.30 & 1.07 \\
$\mathrm{p}$ & $<0.001$ & $<0.50$ & $<0.20$ \\
\hline
\end{tabular}

Table 5 Difference $(d)$ in the mean resonant frequency $(M R F)$ between the control $(N) M R F$ and that of groups 1 and 2 during spontaneous relaxation after decerebrate rigidity

\begin{tabular}{lccl}
\hline & \multicolumn{2}{c}{ Spontaneous relaxation } & \\
\cline { 2 - 3 } & \multicolumn{1}{c}{$N$} & 2 & $N$ \\
\hline MRF $(\mathrm{Hz})$ & 2.99 & 2.45 & 2.34 \\
$\mathrm{~d}(\mathrm{~Hz})$ & 0.65 & 0.11 & \\
$\mathrm{df}$ & 25 & 25 & \\
$t$ & 4.35 & 0.97 & \\
$\mathrm{p}$ & $<0.001$ & $<0.20$ & \\
\hline
\end{tabular}

spontaneous relaxation was highly significant and not significantly respectively (table 5 ).

The increase in compliance of the relaxed limb as compared with the maximally rigid limb was considerable and was greatest in the paralysed limb (Table 3). Compliance was calculated as being proportional to the reciprocal of the square of the resonant frequency (Thomson, 1964).
Effect of muscle relaxants on resonant frequency In all cases $(11 / 13)$ to whom it was administered pancuronium abolished decerebrate rigidity within two minutes approximately. This was tested clinically and verified on EMG. When muscle paralysis had been accomplished the RF was significantly decreased and varied from 1.3$1.9 \mathrm{~Hz}$ (mean RF $1.8 \pm 0.17 \mathrm{~Hz}$ ). The level of relaxation was significantly higher than that obtained with diazepam $(t=2.63, \mathrm{p}<0.025)$ and chlorpromazine $(t=3.60, \mathrm{p}<0.005)$. Diazepam was given in three cases whose mean RF was reduced $(2.1 \pm 0.14 \mathrm{~Hz})$ and chlorpromazine in two cases whose mean RF was reduced to $2.25 \mathrm{~Hz}$ (table 3 ). The level of relaxation achieved with both drugs was not significantly different $(t=1.38, \mathrm{p}<0.2)$, especially with chlorpromazine it was unstable and the patient required frequent, repeated doses to maintain muscular relaxation.

\section{Discussion}

LOW FREQUENCY SQUARE WAVEFORM TORQUES

Bursts of motor unit activity $(8-12 \mathrm{~Hz})$ from various skeletal muscles during voluntary contractions have been observed in EMG studies by many investigators. A physiological tremor of 8-12 $\mathrm{Hz}$ has been recorded during such muscle contractions from the extended third digit (Lippold, 1970), the partially extended flexed forearm (Fox and Randall, 1970), and the soleus 
during "quiet standing" (Morri, 1973). The tremor frequency may be decreased by adding mass as in the experiments of Fox and Randall (1970), or be relatively little affected by load (Robson, 1959). These observations suggest that there are two types of tremor-in one the frequency is loaddependent, in the other it is not.

The oscillatory transients observed after sudden displacement of the wrist in the normal subjects during contraction and in the patients exhibiting decerebrate rigidity were in the range $8-12 \mathrm{~Hz}$. It is likely that they represent a masked tremor, the mechanism of which may possibly be the same as in overt tremor. If this is the case the tremor appears to be load-dependent as it decreases on adding mass to the system. Oscillatory transients have been seen and studied extensively in mechanical servo systems when they were subjected to sudden displacement. This effect is called "ringing or howling" and appears when the system becomes unstable (Bayliss, 1966).

The passively displaced hand resists movements because of (a) inertia, (b) viscoelastic properties of its muscles and joints (essentially what we describe as muscle tone), and (c) its stretch reflex activity. All these three processes affect the wrist compliance. As inertia remained unaltered, the wrist compliance was dependent on viscoelasticity and reflex activity. Although compliance has been widely used in mechanical systems as an index of elasticity, its measurement in complex biological systems presents problems. The great scatter of compliance values between individuals which we saw in our study is a serious disadvantage with regard to its use as an accurate and reliable index of muscle tone. Marked fluctuations in muscle tone may yet fall within the wide range of normal variation, especially as previous studies of the state of our patients were not available for comparison.

SINUSOIDAL TORQUES OF LOGARITHMICALLY VARYING FREQUENCY

A servo control system oscillates when its input is oscillated over a suitable range of frequencies. If the input amplitude is kept constant while the frequency is varied, the output amplitude increases to a maximum value, ie resonance occurs, when the input frequency is near the natural frequency of the oscillating system (Cunningham, 1958).

Since the mass of the hand remains unchanged, its resonant frequency depends on the viscoelastic resistance with which the soft tissue of the system reacts to the displacement. This resistance, which is the muscle tone, cannot, however, be measured directly during oscillatory movements as factors such as the force required to move the mass of the hand, complicate the measurement. When resonance occurs, however, the inertia caused by the mass is balanced by the viscoelastic properties of the limb and the elastic resistance can be measured directly. In other words, at resonance the resonant frequency is the "natural frequency" of the system.

The RF of the wrist in a few normal relaxed subjects, as described by Walsh (1977), varied between 2.0 and $2.5 \mathrm{~Hz}$. Maximal clenching of the fist raised it to $13.0 \mathrm{~Hz}$, whereas in a professional pianist it reached $16.0 \mathrm{~Hz}$.

The observation that during spontaneous relaxation in cases with decerebrate rigidity the RF was higher than in normal relaxed subjects, indicates that although the muscles appear to be at rest between spasms, this is not, in fact, the case.

On mechanical ventilation and curarisation the RF fell to well below $2.0 \mathrm{~Hz}$, less than was seen in any of our volunteer subjects or in any decerebrate patient after either diazepam or chlorpromazine. It has been reported that in a very few normal, paralysed subjects the RF did not fall below $2.0 \mathrm{~Hz}$ (Walsh, 1977). This suggests that pancuronium is more effective in the decerebrate patient than in the normal subject but Walsh agrees (personal communication, 1978) that his findings may have been anomalous and certainly insufficient in number for valid conclusions to be drawn.

A value of less than $2.0 \mathrm{~Hz}$ for the $\mathrm{RF}$ of the wrist thus appears to be distinctly unusual under any normal circumstances. The method may be useful in the clinical assessment of muscular hypotonia as well as of rigidity. Estimation of muscle tone by measuring the RF is reliable and reproducible, and has a theoretical basis in current concepts of neuromuscular control mechanisms.

\section{COMPARISON OF THE TWO METHODS}

A disadvantage of the resonance method as compared with applying a simple step function (square wave) is that the measurement takes longer to accomplish, and the system thus measured may vary its level of function during the period of measurement. This is particularly true of sharply resonant systems where a bias may be introduced if the rate of change of frequency during the sweep is too great. The duration of sweep used in this study (eight seconds) represents a compromise between the requirements of accuracy and speed. The technique has been validated by using different sweep speeds as described. 
The use of square waves allows a continuous sequence of measurements of displacement from which estimates of tone are obtained, so that in spite of the wide scatter of results useful estimates of changes in tone can be obtained.

We consider that the difference in tonicity measurements obtained by the two methods is the result of differences in the phenomena measured. It is unlikely that inertia or viscoelasticity will alter, so it must be a difference in stretch reflex activity. This has been shown to be produced when square waveform torques produced a sudden displacement of the hand whereas with sinusoidal torques myotatic activity was not observed. It is known that this reflex activity is load-dependent and the threshold for eliciting it is much lower in spastic and decerebrate cases (Matthews and Stein, 1969).

A Syme Surgical Fellowship, Medical Faculty, University of Edinburgh, to SAT is acknowledged gratefully. We thank $\mathrm{Dr} \mathrm{H}$ Townsend, Department of Electrophysiology and Electroencephalography, University of Edinburgh, for reviewing this paper critically. Advice and help were given during this work by Dr E G Walsh, Department of Physiology, University of Edinburgh. Mr G Wright provided skilful assistance during the recordings.

\section{References}

Agarwal, G. C., and Gottlieb, G. L. (1975). Forced oscillations of the ankle joint. In Proceedings of the International Occupational Hand-arm Vibration Conference, pp. 50-59. Edited by D. E. Wasserman and M. G. Curry. U.S. Department of Health, Education, and Welfare, National Institute for Occupational Safety and Health: Cincinnati, Ohio.

Bayliss, L. E. (1966). Living Control Systems, pp. 5758. English University Press: London.

Bertholz, A., and Metral, S. (1970). Behavior of a muscular group subjected to a sinusoidal and trapezoidal variation of force. Journal of Applied Physiology, 29, 378-394.

Brumlic, J., and Boshes, B. (1961). Quantitation of muscle tone in normals and in Parkinsonism. Archives of Neurology (Chicago), 4, 399-406.

Cunningham, W. J. (1958). Forced oscillating systems. In Introduction to Non-linear Analysis, pp. 171220. Edited by W. J. Cunningham. McGraw-Hill: New York.

Duggan, T. C., and McLellan, D. L. (1973). Measurement of muscle tone: a method suitable for clinical use. Electroencephalography and Clinical Neurophysiology, 35, 654-658.

Evarts, E. V. (1967). Representations of movements and muscles by pyramidal tract neurons of the pre- central motor cortex. In Neurophysiological Basis of Normal and Abnormal Motor Activities, pp. 215253. Edited by M. D. Yahr and D. P. Purpura. Raven Press: New York.

Fox, J. R., and Randall, J. E. (1970). Relationship between forearm tremor and biceps electromyograms. Journal of Applied Physiology, 29, 103-108.

Granit, R. (1970). The Basis of Motor Control. Academic Press: New York.

Granit, R. (1975). The functional role of the muscle spindles-facts and hypotheses. Brain, 98, 531-556.

Harris, P., and Walsh, E. G. (1972). Stimultaneous electrical and mechanical recording from postural muscles in a paraplegic patient. Paraplegia, 9, 229230.

Hoefer, P. F. A., and Putman, T. J. (1940). Action potentials of muscles in rigidity and tremor. Archives of Neurology and Psychiatry (Chicago), 43, 704-725.

Jansen, J. K. S., and Rack, P. M. H. (1966). The reflex response to sinusoidal stretching of the soleus in the decerebrate cat. Journal of Physiology, 185, 15-36.

Jansen, J. K. S., and Rudjord, T. (1964). On the silent period and Golgi tendon organs of the soleus muscles of the cat. Acta Physiologica Scandinavica, 62, 364-379.

Joyce, G. C., Rack, P. M. H., and Rose, H. F. (1974). The forces generated at the human elbow joint in response to imposed sinusoidal movements of the forearm. Journal of Physiology, 240, 351-374.

Levine, I. M. (1964). (Secretary) Symposium on skeletal muscle hypertonia. Clinical Pharmacology and Therapeutics, 5, 879-941.

Levine, I. M., Jossman, P. B., De Angelis, V., and Kane, M. (1964). Quantification of the electromyogram in neurospastic disorders. Clinical Pharmacology and Therapeutics, 5, 893-899.

Lippold, O. C. (1970). Oscillation in the stretch reflex arc and the origin of the rhythmical 8-12 c/s component of the physiological tremor. Journal of Physiology, 206, 359-382.

Machin, K. E., and Pringle, J. W. S. (1960). The physiology of insect fibrillar muscle. III. The effects of sinusoidal changes of length on a beetle flight muscle. Proceedings of the Royal Society, B, 152, 45-64.

Matthews, P. B. C., and Stein, R. B. (1969). The sensitivity of muscle spindle afferents to small sinusoidal changes. Journal of Physiology, 200, 723743.

Morri, S. (1973). Discharge patterns of soleus motor units with associated changes in force exerted by foot during quiet stance in man. Journal of Neurophysiology, 36, 458-471.

Nashold, B. S. (1966). An electronic method of measuring and recording resistance to passive muscle stretch. Journal of Neurosurgery, 24, 310. 314.

Nashold, B. S., and Huber, M. V. (1966). (Editors). The second symposium on Parkinson's disease. 
Journal of Neurosurgery, 24, Supplement II, 298319.

Roberts, T. D. M. (1963). Rhythmic excitation of a stretch reflex, revealing (a) hysteresis and (b) a difference between the responses to pulling and to stretching. Quarterly Journal of Experimental Physiology, 197, 328-345.

Robson, J. G. (1959). The effect of loading upon the frequency of muscle tremor. Journal of Physiology, 149, 29-30P.

Sherrington, C. S. (1909). On plastic tonus and proprioceptive reflexes. Quarterly Journal of Experimental Physiology, 2, 109-156.

Terzuolo, C. A., and Poppele, R. E. (1968). Myotatic reflex: its input-output relation. Science, 159, 743745.

Thomson, W. T. (1964). Mechanical Vibrations, second edition, p. 20. Allen and Unwin: London.

Walsh, E. G. (1970a). Tremor of the wrist induced by positive velocity feed-back. Journal of Physiology, 207, 16-17P.

Walsh, E. G. (1970b). Movements of the jaw result- ing from the application of external forces. Journal of Physiology, 210, 179-180P.

Walsh, E. G. (1971). Ankle clonus-an autonomous central pace-maker? Journal of Physiology, 212, 38-39P.

Walsh, E. G. (1973). Motion at the wrist induced by rhythmic forces. Journal of Physiology, 230, 4445P.

Walsh, E. G. (1974). A torque-induced motion analyzer. Journal of Physiology, 244, 14-15P.

Walsh, E. G. (1977). Persistence of stretch reflexes following cerebellar ablation and a resonance theory of cerebellar function. In Physiological Aspects of Clinical Neurology, pp. 215-244. Edited by F. R. Rose. Blackwell Scientific Publications: Oxford.

Webster, D. D. (1964). The dynamic quantitation of spasticity with automated integrals of passive motion resistance. Clinical Pharmacology and Therapeutics, 5, 900-908.

Wilkie, D. R. (1950). The relation between force and velocity in human muscle. Journal of Physiology, 110, 249-280. 